\title{
LAS TALLAS GRANDES PERJUDICAN SERIAMENTE LA SALUD La frágil legitimidad de las prácticas de adelgazamiento entre las madres de clases populares
}

\author{
BIG SIZES ARE HAZARDOUS TO YOUR HEALTH \\ The Weak Legitimacy of Weight Control Practices in Working Class Mothers
}

\author{
EnRIQUe Martín CRIAdo \\ Universidad de Sevilla. España \\ martincriado@gmail.com
}

\begin{abstract}
RESUMEN
El artículo defiende la potencialidad de un análisis que considere los discursos como jugadas estratégicas. Para ello parte de las oscilaciones y contradicciones en los discursos de madres de clases populares en torno al control del peso: la pretensión de adelgazar se afirma y se niega. Estas contradicciones se deben a su difícil posición entre dos normas contradictorias: la norma de delgadez y el valor de buena madre entregada. La tensión entre ambas nos permite entender las oscilaciones del discurso, pero también sus prácticas. Éstas intentan conciliar el cuidado de sí con la legitimidad de la buena madre.
\end{abstract}

\section{Palabras Clave}

Alimentación, Análisis de discurso, Dieta, Género, Obesidad.

\begin{abstract}
The article defends an analysis that considers discourses as strategic moves. It takes as an example the discursive oscillations and contradictions on weight control of working class mothers: the intention to lose weight is asserted and denied. These contradictions are due to their difficult position between two contradictory norms: the slimness norm and the value of the sacrificed good mother. The tension between both norms allows us to understand discourse oscillations, as well as practices. These try to balance the care of the self with the legitimacy of the good mother.
\end{abstract}

\section{KEYWORDS}

Alimentation, Diet, Discourse Analysis, Gender, Obesity. 


\section{INTRODUCCIÓN}

El analista de grupos de discusión suele encontrarse ante numerosas contradicciones y oscilaciones en los discursos de los participantes: lo que en un momento se afirmó, más tarde se niega ¿Cómo analizar estos vaivenes discursivos?

Varias soluciones se perfilan. Una común es seleccionar aquellos discursos que al analista le parezcan "la verdad" de los sujetos. Los sujetos hablarían, en algún momento, "de verdad": el resto de su discurso sería una máscara, una concesión a las convenciones, falsedades interesada. Bajo estas máscaras, el analista buscaría un discurso "auténtico": en él encontraríamos las verdaderas prácticas del sujeto, sus verdaderas razones, sus "valores" y "actitudes".

Otra posible solución es no desechar ningún enunciado: el analista acumularía y etiquetaría las distintas afirmaciones como otras tantas "opiniones", "actitudes" o "razones" de los sujetos. Hilvanando estas afirmaciones con conjunciones - "opinan que... pero también"-, el problema se disolvería con fáciles gramáticas. También podría acudir a emblemas de cientificidad: contando las frecuencias de las distintas "opiniones", las "verdaderas" serían las más repetidas.

Muy distinto es el camino que ilustraré en este artículo. En él se parte de una concepción diferente del discurso y de la explicación de las prácticas.

En primer lugar, los discursos no son "expresiones de actitudes, opiniones", etc., sino "jugadas" estratégicas de los sujetos para presentarse en público y manejar su imagen. En función de los interlocutores, de la "censura estructural" de la situación (Bourdieu 1985), los sujetos producirán unos discursos u otros.

Esta pluralidad discursiva no ha de conminarnos a buscar un discurso auténtico. Por una parte, los sujetos, en sus prácticas, ponen en juego esquemas heterogéneos: lejos de ser sujetos unificados y coherentes, son sujetos plurales (Lahire 1998). Por otra parte, si sus discursos están sometidos a una "censura estructural" por el hecho de hallarse en una situación de "visibilidad" — todo lo que diga puede ser utilizado en su contra-, lo mismo ocurre con el resto de prácticas: éstas también se juegan en espacios de visibilidad, también son juzgadas, también varían según la situación ${ }^{1}$.

Las oscilaciones y contradicciones del discurso no son aquí algo a disolver o a contabilizar. Por el contrario, conforman el objeto del análisis. No sólo para comprender los vaivenes del discurso: nos ofrecen también valiosos elementos para entender las prácticas. Prácticas y discursos ponen en juego tensiones: entre las distintas normas 0 legitimidades que pesan sobre las prácticas, entre lo que se piensa que se debería hacer y lo que se hace - que se aleja siempre de lo que se percibe como legítimo, porque los sujetos no actúan únicamente a partir de valores, sino también a partir de las constric-

\footnotetext{
${ }^{1}$ Sobre los fundamentos teóricos de análisis de discurso de los análisis que siguen véase Martín Criado 1991; 1997; 1998.
} 
ciones de la situación-. Analizar las oscilaciones del discurso nos permite comprender las oscilaciones de las prácticas.

Mostraré este tipo de análisis con un ejemplo: los discursos de madres de clases populares en torno al control del peso corporal. Tras presentar los datos generales de la investigación en que se basa este análisis, plantearé el problema a investigar: los vaivenes en los discursos en torno al control del peso. Para comprenderlos, abordaremos dos temas: el valor de la buena madre y los cambios en la concepción de la salud. A partir de ellos, analizaremos las oscilaciones en los discursos, que nos permitirán reconstruir el juego de tensiones a que se hallan sometidas las prácticas ${ }^{2}$.

\section{Metodología}

El material empírico en que se basa este artículo procede de una investigación sobre Prácticas y discursos sobre alimentación en las clases populares en Andalucía realizada, con José Luis Moreno Pestaña, en 2003, para la Dirección General de Salud Pública de la Consejería de Salud de la Junta de Andalucía. La investigación se realizó con grupos de discusión en distintas poblaciones. El primer criterio delimitador fue que la población perteneciera a las "clases populares": este término, de límites difusos, se tradujo en dos características principales: trabajo manual (asalariado o autónomo); nivel de estudios secundario o inferior.

Los grupos se iniciaron con una pregunta general: “¿Hemos logrado tener una alimentación sana?". Se pretendía que el grupo definiera por sí mismo los temas de interés. El preceptor se limitó a relanzar algunos temas.

En el diseño de los grupos se tuvieron en cuenta: género; edad; hábitat (rural o urbano); división, en las mujeres adultas, entre las que trabajaban fuera del hogar y las que no. Se realizaron once grupos de discusión. Este artículo se basa en los seis realizados con mujeres adultas:

GD1: Amas de casa, 42-58 años, Cerro del Andévalo. Todas tenían hijos de entre 15 y 30 años. Todas con estudios primarios, excepto una, con FP I (Formación Profesional). Sus maridos, obreros, excepto dos empleados administrativos.

GD2: Mujeres de 37 a 42 años, Conil de la Frontera. Amas de casa; excepto una dueña de un bar y una auxiliar de clínica. Todas, excepto una, tienen hijos, de entre 7 y 21 años. La mitad tiene estudios primarios, la otra mitad COU (Curso Orientación Universitaria) o FP-I (Formación Profesional). Los maridos, trabajadores manuales autónomos, excepto uno -empleado de banca.

\footnotetext{
${ }^{2}$ Una primera versión de este artículo se presentó en el IX Congreso Español de Sociología. José Luis Moreno Pestaña y Hélène Bretin aportaron valiosas críticas y sugerencias a aquella primera versión. Desde aquí les expreso mi agradecimiento.
} 
GD3: Mujeres a dieta, de 39-50 años, Sevilla. Grupo realizado con mujeres que habían seguido un régimen de adelgazamiento durante al menos un mes. Mayoría de amas de casa con dos trabajadoras (empleada de hogar, comercial). Dispersión en nivel de estudios: sin estudios, primarios, bachillerato, Formación Profesional I. Maridos obreros 0 empleados, con estudios primarios o secundarios. Todas tienen hijos, de entre 11 y 27 años.

GD4: Mujeres de 35 a 41 años, Dúrcal. Todas tienen estudios primarios, excepto una con FP-I y otra -errores de la captación — con estudios universitarios. Todas tienen hijos, de entre 11 y 17 años. Sus maridos, con estudios primarios, tienen trabajos manuales, asalariados o autónomos - excepto el marido de la licenciada, profesor de Instituto.

GD5: Mujeres de 42-55 años, Linares. Todas tienen estudios primarios y son amas de casa, excepto una con Formación Profesional que trabaja como auxiliar de clínica. Todas tienen hijos de entre 10 y 30 años. Los cónyuges son obreros con estudios primarios, excepto uno, apoderado de banco.

GD6: Mujeres trabajadoras, 31-44 años, Sevilla. Excepto una, todas están casadas y tienen hijos de entre 3 y 15 años. Todas tienen estudios primarios, excepto la soltera, con BUP (bachiller). Asalariadas con trabajos manuales. Los cónyuges son trabajadores manuales - asalariados o autónomos-, con estudios primarios, excepto uno con Formación Profesional.

\section{LA PROBLEMÁtICA LEGITIMIDAD DEL DESEO DE ADELGAZAR}

El discurso de los grupos gira en torno a dos temáticas: la alimentación de los hijos y la preocupación por adelgazar. Mientras la primera ocupa el centro del escenario, la segunda salpica constantemente el discurso: son constantes las referencias a evitar alimentos grasos, a los trucos para perder peso, a las restricciones cotidianas o esporádicas. Del discurso médico sobre nutrición, lo más mencionado es lo relacionado con el control de peso. La información nutricional está tan vinculada al control del peso que dieta y dietética son sinónimos de régimen de adelgazamiento; asimismo, uno de los criterios principales para identificar los alimentos no sanos es el que engorden ${ }^{3}$.

Sin embargo, cuando la conversación se centra en la delgadez, el discurso cambia radicalmente: serían "otras" las que, "esclavas de las calorías", estarían "obsesionadas" con el control de peso. La preocupación por engordar necesita negarse continuamente:

"A- Yo no es que esté obsesionada, pero yo cuando suba peso sé que tengo que perder peso.

\footnotetext{
${ }^{3}$ Otras investigaciones encontraron resultados similares (Espeitx 2005; Germov y Williams 1996; Charles y Kerr 1988: 127-134).
} 
B- Es lo que te estoy diciendo, que tampoco tienes que obsesionarte con las calorías que consumes

A- Ah, yo no, yo cuando salgo por ahí y a mí me apetece tomarme un helado [...] yo no tengo nada que ver con eso, porque la dieta yo no voy a ser esclava de la vida porque a mí no me da la gana. Yo sé que hay mucha gente esclava de las calorías, porque se tiene que poner una 40 o una 38 por narices [...] Yo ya he asimilado totalmente que voy avanzando de edad y también voy avanzando de constitución". (GD1)

En esta oscilación, sólo una razón justificaría adelgazar: la salud. Frente a aquéllas, frívolas o superficiales, que pretenden aparentar menos años, nosotras sólo nos preocuparíamos por reducir peso cuando tuviéramos problemas físicos tangibles: dolor de piernas, problemas circulatorios, etc 4 . El discurso gira en torno a una cuestión central: ¿Cuándo es legítimo preocuparse por el peso? En esta discusión, todas oponen un cuidado de sí legítimo - por "salud" - y uno ilegítimo — por "estética" - criticando a las que "se miran demasiado", que se "obsesionan" con la "línea". Entre ambos polos, las disputas sobre la legitimidad de adelgazar son constantes y los límites fluctúan incesantemente: se puede acusar a otras de prácticas que una misma reconoce hacer en otro momento, se puede afirmar y negar a la vez el deseo de adelgazar. Para comprender estas oscilaciones, hemos de remitirlas a las legitimidades en juego. Con este fin, nos detendremos en dos esquemas centrales: el de la "buena madre" y el de la relación de la salud con el cuidado de sí.

\section{LA TRANSFORMACIÓN DEL ESQUEMA DE LA BUENA MADRE}

La posición de la mujer ante la alimentación familiar en las clases populares pone en juego un esquema valorativo central: el de la buena madre ${ }^{5}$. Las prácticas de estas mujeres se evalúan constantemente -en el hogar, entre vecinas, amigas, familiaresdesde un modelo de "buena madre" que contrapone aquélla que se "entrega" o "sacrifica" por dar lo mejor a su familia frente a la "cómoda" o "mala madre" que no cumpliría

\footnotetext{
${ }^{4}$ En la siguiente intervención se ve la negación del deseo de adelgazar y su justificación en términos de salud: "Yo por ejemplo mi experiencia, procuro tener siempre el mismo peso, yo engordo dos kilos más, yo no adelgazo porque yo quiera adelgazar, porque yo me note gorda, porque yo en realidad si yo engordo no me quedo gorda, sino es que ya yo me siento pesada, es que ya yo procuro ponerme los zapatos, agachándome para adelante y a mí me molesta el estómago, entonces yo no adelgazo por yo estar más guapa, más elegante, yo adelgazo para mi comodidad, porque yo me lo noto rápido, yo creo que adelgazando dos kilos yo ya no me siento bien, yo me agacho para coger algo, para ponerme el zapato 0 algo y a mí me produce malestar, entonces yo tengo que tener mi peso, no sé si es porque me he acostumbrado a ese peso 0 , pero yo no digo voy a adelgazar porque estoy gorda y quiero mantener la misma talla, no, es porque mi cuerpo me pide tener el mismo peso" (GD2).

${ }^{5}$ En este epígrafe y en el siguiente sintetizamos lo expuesto en Martín Criado y Moreno Pestaña (2005: 19-98).
} 
con estas exigencias. La buena madre ni mide ni calcula este sacrificio; ocupada siempre en el bienestar de su familia, se olvida de sí misma haciendo entrega de su tiempo, su esfuerzo, su cuerpo: supedita sus deseos y necesidades a los de sus hijos y marido ${ }^{6}$. El cuidado del cuerpo de la madre sólo se justifica por problemas de salud: sólo cuando sufre fuertes dolores o enfermedades que la incapacitan o que, por su gravedad, requerirían un cuidado ineludible podría disfrutar del "beneficio de la enfermedad"7 y dispensarse del sacrificio que su posición exige ${ }^{8}$. El tiempo legítimo para el cuidado de sí se limitaría al necesario para mantener su fuerza de trabajo: la madre sólo podría "mirar por sí misma" como medio para mejor cumplir su papel. Frente a ella, la mala madre "se miraría demasiado": relegaría a su familia a un segundo plano en una preocupación desmedida por su cuerpo.

Podemos considerar, siguiendo a numerosas autoras (Badinter 1980; Hays 1988; Kniebiehler 2000), que este esquema legitima la dominación masculina, ensalzando la subordinación femenina a los deseos y necesidades del resto de la familia. Esto es la "entrega": prioridad de los objetivos y necesidades ajenos sobre los propios. Por ello, este esquema simbólico persiste con más vigor en aquéllas más vinculadas a la división tradicional de género: es más probable encontrarlo en forma más extrema entre las mujeres de mayor edad y menor capital escolar 9 . Por ello, este esquema es contestado por otro nuevo modelo de madre que avanza con la redefinición de las relaciones de género hacia una menor desigualdad. En este nuevo modelo la mujer no se reduce a ser madre y ama de casa. Aunque sigue siendo la principal responsable de la salud y bienestar familiares, comparte esta responsabilidad con el cónyuge. Aunque también se le pida una fuerte dedicación a sus hijos ${ }^{10}$, ésta no agota su valor social ni su identidad; la madre es también una mujer con derecho a objetivos — profesionales, de ocio— propios

${ }^{6}$ Dema (2006) muestra cómo incide esta concepción en los gastos familiares: mientras los hombres se ven con derecho a tener gastos propios, las mujeres suelen anteponer las necesidades familiares a las propias. Murillo (1996) resalta lo mismo respecto a la privacidad: ésta suele ser para las mujeres una privación de sí.

${ }^{7}$ Ser calificado como enfermo exime de ciertas obligaciones normales y da derecho a ciertos cuidados (Freidson 1978: 229-233; Herzlich 1984: 215).

${ }^{8}$ Ello lleva a estrategias para obtener la etiqueta de enferma magnificando las dolencias que se sufren. Estas tácticas pretenden un doble beneficio: revalorizarse simbólicamente -se sacrificaron tanto que ahora lo pagan con un sufrimiento extraordinario: se les debe el mayor reconocimiento- $y$ aliviarse de parte de la carga que exige el papel de buena madre.

${ }^{9}$ En los grupos de discusión, las mujeres que representaban este modelo de forma más extrema compartían un nivel de estudios de primaria o inferior; la mayoría eran mayores de 45 años. Numerosas investigaciones muestran que la redefinición de las relaciones de género hacia posiciones menos desigualitarias es más probable a mayor capital escolar (Baudelot et al. 2005: 180-185; Kauffman 1993; Meil 1997; Valiente Fernández 1997).

${ }^{10}$ Solé y Parella (2004) muestran que las mujeres de mayor estatus también comparten el modelo que Hays denomina de "maternidad intensiva", generando sentimientos de culpabilidad cuando la actividad profesional no permite dedicarle a los hijos el extenso tiempo que se considera necesario. 
y a un cuerpo para sí. El cuidado de su cuerpo ya no se supedita a la función maternal. "Hay que quererse, hay que cuidarse": estas fórmulas enuncian una nueva legitimidad del cuidado de sí.

Estos dos modelos, en su forma pura, son minoritarios entre las participantes de los grupos de discusión ${ }^{11}$. La mayoría está en algún punto intermedio, en tensión, entre ambos. El modelo tradicional permanece como referente inexcusable de legitimidad: si una afirma que le dedica mucha atención al propio cuerpo es acusada de "mirarse demasiado". El nuevo modelo legítimo avanza con dificultad: esquivando los ámbitos donde se opone más frontalmente a la legitimidad tradicional, evitando formularse demasiado explícitamente, justificándose por la salud. Esta transformación del modelo de madre difumina las fronteras entre la buena y la mala madre: de ahí su incesante movimiento estratégico, de ahí el interminable debate en torno a la línea que separa el cuidado de sí legítimo del ilegítimo.

\section{TRANSFORMACIONES EN LA CONCEPCIÓN DE LA SALUD}

Otro elemento esencial para comprender estos debates es la transformación en la concepción de salud. Las que más discuten el modelo tradicional de buena madre también mantienen una concepción de la salud más cercana al discurso nutricional y médico, especialmente al preventivo que se extiende en la segunda mitad del s. XX (Herzlich y Pierret 1984: 202-204; Germov y Williams 1996). Podemos resumir esta concepción en la idea de "norma": la salud constituye un estado ideal amenazado constantemente por la enfermedad. Mantener la salud exigiría ceñirse a una delgada línea de comportamiento correcto: cualquier comportamiento desviado de esta línea sería un paso hacia la enfermedad. La enfermedad declarada sería el último eslabón de un deterioro progresivo del organismo producto de estas desviaciones.

Esta concepción de la salud exige, en su extremo ideal, una vigilancia permanente sobre los comportamientos alimentarios; como toda desviación nos acerca a la enfermedad, hay que supeditar la alimentación cotidiana a las prescripciones médicas. Ello exige una disposición ascética que conforma un nuevo baremo del valor de la buena madre: ésta lograría, mediante su constante control, conciliar el cuidado de sí y el cuidado familiar ${ }^{12}$.

\footnotetext{
${ }^{11}$ El modelo tradicional está representado de forma más pura por una participante del GD5, de 55 años, ama de casa con estudios primarios, cónyuge apoderado de banco, y por otra participante del GD4, 40 años, ama de casa, estudios primarios; marido albañil con estudios primarios. El nuevo modelo está representado de forma extrema por la participante del GD4 con estudios universitarios, ama de casa, esposa de profesor de Instituto y por dos participantes del GD2, de 37 y 42 años, ambas y sus cónyuges con estudios de COU.

${ }^{12}$ Una de las condiciones de posibilidad de este control es haber interiorizado la norma nutricional, en forma de gustos y ascos, en las disposiciones corporales. Las mujeres más cercanas a esta posición ostentan su asco por aquellos productos poco recomendables según el discurso médico.
} 
En el polo tradicional, la enfermedad es un estado opuesto al de salud que sobreviene súbitamente. Frente a la continuidad entre salud y enfermedad de la concepción de norma, aquí son dos ámbitos radicalmente separados. La enfermedad constituye un ámbito bien circunscrito de disfunciones físicas que trastornan el funcionamiento cotidiano del cuerpo, incapacitándolo para las tareas ordinarias; en ausencia de estos trastornos, una persona se halla sana. Se pasa de un estado a otro de manera brusca: se "cae enfermo"; la salud se recupera con algún "remedio"13.

Este esquema supone una relación a la salud opuesta a la concepción de norma: mientras uno esté sano, basta guardar unos mínimos. Sólo cuando uno "cae enfermo" ha de poner "remedio". Uno sólo ha de vigilar su alimentación cuando cae enfermo, tomando alimentos-remedio para dolencias específicas o alimentos que dan fuerza ${ }^{14}$ - para superar la "debilidad"-. Esta alimentación especial sólo se mantiene mientras persista la enfermedad: remediada ésta, se vuelve a la comida "normal".

La concepción de salud de la posición tradicional junto a su esquema de buena madre comportan una relación al cuerpo opuesta a la del nuevo modelo legítimo. El cuidado de sí de la madre sólo se justifica ante disfunciones físicas evidentes: en este caso, hay que llevar la alimentación apropiada a la enfermedad. Fuera de este estado bien circunscrito, la alimentación sería la "normal": los productos que han conformado mucho tiempo la dieta de las clases populares -alimentos calóricos de bajo precio (Bourdieu 1988: 176-194; Fischler 1995:175; Grignon y Grignon 1980; González Turmo 1997) — cocinada de la manera tradicional —la alimentación comida desde la infancia, cuyos sabores se han incorporado en un habitus alimentario caracterizado por el gusto por productos calóricos-. Todo empuja así a una alimentación cotidiana contraria a la vigilancia constante del polo legítimo: una oposición reforzada por tres principios desde los cuales se denuncia como inmoral o irracional el constante cuidado de sí.

En primer lugar, el principio de no mirarse demasiado: la que se mira demasiado se da excesiva importancia; pierde el tiempo en "caprichos" ajenos a su función maternal. Todo cuidado de sí que no derive de una enfermedad evidente es inmoral y propio de gente demasiado "delicada". Quien incesantemente vigila su salud adolece de debilidad de carácter: no sabría resistir, mostrar fuerza. De ahí que las participantes de los grupos más cercanas a la concepción tradicional afirmen orgullosas que no se miran, que no se miden la tasa de azúcar o de colesterol, que apenas van al médico. Esta falta de control es signo de vigor físico y moral: la madre sana y entregada no se entretiene en la contemplación morosa de su cuerpo.

\footnotetext{
${ }^{13}$ Esta concepción ha prevalecido mucho tiempo en las clases populares (Boltanski 1975; Adam y Herzlich 2002: 67-69).

${ }^{14}$ Ello se corresponde con las concepciones médicas anteriores al siglo XX (Herzlich y Pierret 1984: 145146). También se corresponde con la escasez de alimentos que ha amenazado periódicamente a gran parte de la población hasta recientemente.
} 
En segundo lugar, el principio de saber disfrutar. El verdadero goce de la vida consistiría en disfrutar del presente: el cálculo continuo, la restricción constante son contrarios a la verdadera vida.

En tercer lugar, el principio de la buena boca. Quien tiene buena boca disfruta de todos los alimentos: sin "caprichos" ni "remilgos" puede ir a todas partes y comer lo que hay. El principio de la buena boca articula el valor de la integración en el grupo -el que tiene buena boca come lo que todo el mundo, no se distingue por gustos o ascos especiales—, el valor de la supervivencia —quien tiene buena boca ha adquirido el principio de escasez ${ }^{15}$ : nunca pasará hambre porque será capaz de comer allí donde esté- y el valor de saber disfrutar —comerá con gusto y en abundancia, sin "remilgos", lo que hay-. Frente a él está el "delicado", el "remilgado" que no ha incorporado el principio de escasez y que se aparta del gusto común manifestando distancia, incluso rechazo.

Estos tres esquemas, junto al valor de la entrega, se oponen al cuidado de sí del nuevo modelo. Las madres más próximas a éste son acusadas de mirarse demasiado, de descuidar a sus hijos, de carácter débil, de creerse demasiado importantes, de no saber disfrutar.

La mayoría de las participantes en los grupos de discusión se halla en una posición intermedia entre el "polo tradicional" y el nuevo "polo legítimo". Primero, respecto al cuidado de sí. Aunque se adhieren a las acusaciones de las más tradicionales contra aquéllas que "se miran demasiado", están dispuestas a acoger aquellos argumentos que les permitan legitimar nuevas prácticas de cuidado de sí: entre las madres más cercanas al nuevo polo legítimo y el resto se juega una relación ambivalente, de atracción y repulsión. Posición intermedia, también, en su concepción de la salud. En principio, ésta deriva de la concepción de norma: los malos hábitos deterioran progresivamente el cuerpo. Sin embargo, aquí la línea de los comportamientos sanos es mucho más ancha; la enfermedad no llega por una sucesión de pequeñas desviaciones, que no tendrían repercusiones, sino por "excesos, abusos": Por comportamientos que se alejen más de lo sano de lo que se hace efectivamente ${ }^{16}$. Esta concepción permite compatibilizar la noción de norma con un comportamiento cotidiano muy alejado de la vigilancia constante del polo legítimo. Aunque aquí la enfermedad ya no consiste, como en el polo tradicional, únicamente en disfunciones físicas evidentes. Se puede estar enferma sin sentir molestias ni dolores: las tasas elevadas en valores como el colesterol o el azúcar se asimilan a enfermedades, a estados donde una ha de cuidarse. Esta evolución será fundamental para comprender las formas de legitimar el cuidado de sí.

\footnotetext{
${ }^{15}$ El principio de escasez ha constituido durante mucho tiempo un esquema básico de percepción y apreciación de las clases populares. Este esquema convierte la experiencia de la escasez en valor positivo: una persona es mejor cuanta mayor capacidad tenga de adaptación a las privaciones. Frente a ella, la persona "caprichosa" carecería de verdadera "experiencia" — no habría aprendido mediante el sufrimiento y la privación-y, por ello, no sabría "darle valor" a las cosas y sería incapaz de enfrentarse a la "vida verdadera" -consistente en privaciones y sufrimientos.

${ }^{16}$ Para un análisis del uso estratégico de "exceso", véase Martín Criado (2004).
} 


\section{LA OPOSICIÓN ENTRE SALUD Y ESTÉTICA}

Ahora podemos volver a las oscilaciones discursivas respecto al control del peso. Como vimos, las referencias a la inquietud por adelgazar son constantes, mostrándonos la importancia de la nueva norma corporal de delgadez. Pero cuando la discusión se centra en el control del peso, todas niegan tal preocupación atribuyéndosela a "otras" - las adolescentes ${ }^{17}$, las malas madres frívolas- Cuando se confiesa un deseo de adelgazar, éste se justifica por dolores o incapacidades físicas: cuando gano unos kilos, "me siento pesada, "me cuesta subir las escaleras", "me cuesta agacharme". Estos enunciados nos revelan la persistencia del modelo tradicional de buena madre: ésta sólo se cuida en caso de incapacidad física. La salud se opone a la estética como la buena a la mala madre, como la que sabe estar en su posición a la que quiere comportarse como si no tuviera responsabilidades familiares, como una "joven". De ahí que el objeto privilegiado de crítica sean aquellas que pretenden aparentar menor edad: se entretienen en frivolidades impropias de una madre. Frente a ellas, nosotras sabríamos estar en nuestro sitio, aceptaríamos nuestra edad y el deterioro del cuerpo con el tiempo.

La mayoría formula esta crítica desde los esquemas de "no mirarse demasiado", "saber disfrutar" y tener "buena boca". Pero las participantes más próximas al polo legítimo también se unen a la crítica, oponiendo los valores "auténticos" de la "persona" a la "superficialidad" de quien se preocupa por las "apariencias". Cuando se trata de las razones de adelgazar, la legitimidad tradicional y la nueva unen sus fuerzas convirtiendo la discusión en un campo de minas: cualquier paso en falso puede activar la acusación de frívola, superficial o mala madre. De ahí que el discurso oscile tanto, que afirme y niegue la preocupación por adelgazar, que se parapete tras dolores 0 incapacidades físicas o que recurra a fórmulas como la del cuerpo parlante ${ }^{18}$.

\footnotetext{
${ }^{17}$ En otro grupo de discusión de la investigación, realizado con chicas de 17-19 años, estudiantes de secundaria, hijas de agricultores y obreros, la pretensión de adelgazar goza de legitimidad como algo propio de la clase de edad.

${ }^{18}$ Este discurso aparece en varias ocasiones en los grupos: tú no debes preocuparte por tu peso, sino escuchar a tu cuerpo; él te dirá lo que verdaderamente necesitas. Sin embargo, lo que este cuerpo parlante suele decir es si engorda o adelgaza: "A mí me parece que las calorías que tú tienes que consumir no son las que te diga fulanico ni menganito ni las que te diga una tabla, tú lo que debes de comer es lo que vayas a consumir y la dieta que adelgaza es la que queda en el plato y olvídate de todo lo demás. Tú no necesitas comer caldo, no lo comas y tu organismo te va a responder. Si tú empiezas a comer a discreción y empiezas a engordar, tu cuerpo te está diciendo que estás comiendo más de la cuenta [...] Yo una vez dejé de comer pan, una vez y dije, oye, si no he perdido ni un gramo, seguí comiendo mi pan ¿qué quiere decir? Que yo como bien, mis comidas no me falta ninguna, merienda y cena, almuerzo y desayuno, y si a media mañana hay que picotear yo picoteo [...] No como con ansia, yo como mi primer plato, yo tampoco... a mí no me ha llegado nunca a obsesionar de decir, a lo mejor en algún momento tengo que bueno, tengo que perder peso, porque tengo algún problema en la... en la..." (GD1).
} 


\section{EL PESO DE LOS CUERPOS DESVALORIZADOS}

Un aspecto esencial de la dinámica de los grupos de discusión es el vaivén de la censura estructural. Si en un momento todos los participantes compiten por demostrar su adecuación a lo legítimo, en otros momentos, tras un juego de tanteos, pueden levantarse las censuras más fuertes: en realidad, se viene a decir, ninguno de nosotros nos conformamos a esta legitimidad -somos cómplices-. Esta dinámica se aprecia claramente en los grupos que estamos analizando. El discurso sobre la salud como razón para adelgazar deja paso, al levantarse las censuras más fuertes, a otro muy distinto: no nos sentimos a gusto estando gordas, queremos perder peso. Este discurso suele aparecer en relación con la ropa: no encontramos prendas bonitas para nuestra talla; el vestido del año pasado quedó estrecho.

Este discurso nos muestra que las razones de salud no suelen ser las prioritarias. Mucho más importante es la valoración social de los distintos tipos de cuerpo. Sería simplistadespachar este elemento etiquetándolo de preocupación "estética". La valoración que uno recibe por lo que es y hace es el elemento fundamental de la autovaloración y la autoestima. La relación continua con otras personas nos recuerda constantemente lo que somos: lo que somos a ojos de los demás. Y el cuerpo es el elemento central, el más visible, de nuestra "fachada" cotidiana (Goffman 1971). La valoración que reciba nuestro cuerpo constituye un elemento esencial de nuestra autopercepción, de nuestro sentimiento de bienestar o malestar con nosotros mismos. De ahí la repetición de las mismas experiencias: oír "parece que estás más gorda" te "baja la moral"; bajar dos kilos "te alegra", te "anima"19. Lo que se juega aquí es el sentido del propio valor social y la autoestima (Charles y Kerr 1988: 143-146; Germov y Williams 1999; Gracia 2007).

No se escapa fácilmente a la nueva norma de delgadez: toda interacción nos la puede recordar ${ }^{20}$. Y también los objetos, como la ropa. Ésta adquiere centralidad discursiva porque muestra nuestra posición en la jerarquía social de cuerpos: necesitar una talla mayor supone un descenso simbólico hacia el infierno de las gordas, no encontrar ropa de la propia talla en las tiendas de moda - y tener que buscar ropa "de vieja" o, peor, recurrir a tiendas especializadas en grandes tallas- es haber traspasado las puertas

\footnotetext{
${ }^{19}$ EI GD3 reunió a mujeres que habían seguido dietas de adelgazamiento. Aquí el cuidado por adelgazar gozaba de entrada de mayor legitimidad: las razones de salud dejaron paso de inmediato al discurso sobre la valoración social de los cuerpos y la autoestima. Una participante, que había seguido sin éxito sucesivas dietas de adelgazamiento, escondía los espejos en su casa para evitar ver su cuerpo. Su ánimo subía cuando las dietas comenzaban a dar resultados -yo pierdo tres kilos y soy la mujer más feliz del mundo, además me pinto, me arreglo, me pongo tacones que no los aguanto, todo-, pero se hundía en la desesperación cuando recuperaba peso. En su afán de adelgazar, era capaz de seguir cualquier régimen aunque supiera que era peligroso para la salud: evitar la desvalorización social del cuerpo era el objetivo prioritario. He analizado este caso en Martín Criado (2007).

${ }^{20}$ Sobre la extensión de la delgadez como nueva norma estética corporal, Stearns (2002); Schwartz (1986); Fischler (1995, cap. 13); Levenstein (1988; 2002); Contreras (2005).
} 
de este infierno. A través de las tallas y los modelos, la ropa incorpora los criterios sociales de valoración de los cuerpos: mirada ajena convertida en objeto, se convierte en alabanza o reproche.

La ropa nos muestra otro aspecto esencial: la presión hacia los cuerpos delgados es un imperativo externo, que convive con una cotidianeidad donde todo empuja en el sentido contrario. Para la mayoría, el imperativo de la delgadez no está incorporado hasta el punto de pesar en las prácticas cotidianas: es inducido por la mirada externa. De ahí, el control discontinuo. De ahí, que la presión hacia la delgadez sólo se imponga cuando algún marcador externo recuerda los kilos ganados, ya sea un objeto —la ropao la mirada ajena - que juzga los cuerpos expuestos en la ropa veraniega o en la playa.

Esta diferencia entre el imperativo hecho cuerpo y el imperativo externo les confiere ventaja, en la discusión sobre la legitimidad de preocuparse por adelgazar, a las más próximas al nuevo modelo nutricional y estético. Éstas pueden ostentar su despreocupación por controlar su peso - porque forma parte de sus hábitos cotidianos-, tachando los esfuerzos del resto de "obsesión" por las "apariencias". Estas participantes esgrimen un discurso de la "autenticidad" que funciona como signo de distinción entre las que adecuan su comportamiento a la norma legítima de forma "natural" y las que han de esforzarse por acercarse a ella.

\section{HACIA EL CUIDADO DE Sí}

El nuevo ideal de delgadez es fuertemente resentido por las participantes que no se adecúan a é ${ }^{21}$. Pero esta presión tiene problemas para enunciarse abiertamente, al hallarse en tensión con la legitimidad tradicional de la buena madre. De ahí todas las oscilaciones y contradicciones discursivas, de ahí el afán por aducir razones de salud o que, en todos los grupos, el ideal sea la delgadez "genética"22.

Sin embargo, cuando la censura estructural se relaja, esta preocupación también encuentra fórmulas para justificar el cuidado de sí o para hallar "formaciones de compromiso"23 entre la legitimidad de la buena madre y el deseo de evitar un cuerpo desvalorizado.

\footnotetext{
${ }^{21}$ Evidentemente, no todas las participantes en los grupos están "gordas". Sus grados de corpulencia son muy variados. Pero la mayoría se aleja del estricto ideal de delgadez dominante, por lo que la experiencia común -con grados variables- es tener "kilos de más". Esto parece haberse extendido en todos los medios sociales de los países desarrollados: Germov y Williams (1996) hablan de una "epidemia de mujeres a dieta".

${ }^{22}$ Aquellas participantes delgadas que no practican -o niegan practicar- restricciones alimentarias alardean de ello: yo estoy delgada, pero por "constitución". La delgadez genética permite conciliar un cuerpo socialmente valorizado con la legitimidad de la buena madre y de la buena boca. Parafraseando la famosa copla, la española cuando es delgada, es delgada de verdad (por genética), y a ninguna le interesa adelgazar por frivolidad.

${ }^{23}$ Freud denominaba "formaciones de compromiso" a las elaboraciones del inconsciente que se disfrazan para acceder a la conciencia sorteando la censura del super-yo. Bourdieu (1985: 52) aplica esta fórmula a aquellos enunciados mediante los que el sujeto intenta adecuar lo que quiere decir -que no sería aceptable si se expresase claramente- a la censura estructural de la situación.
} 
La primera forma es la alusión directa a la desvalorización de los cuerpos gordos. Esta se expresa de dos maneras. Primero, como una preocupación por estar más guapa, pero aludiendo a la autoestima, al estado de ánimo. Fórmula intermedia entre la salud y la estética, la mención de la alegría por perder peso o del abatimiento por ganarlo permiten esquivar -de forma precaria ${ }^{24}$ - la acusación de frivolidad postulando la salud psíquica como una razón legítima para esta preocupación. En segundo lugar, como una obligación impuesta desde fuera: las responsables serían las empresas, la publicidad, "la sociedad". Esta fórmula permite descargarse de culpabilidad -no es que "yo quiera" adelgazar, es que "no puedo no querer" adelgazar porque me siento estigmatizada - inculpando a agentes externos. Pero también es una forma precaria: puede ser acusada de "dejarse influenciar" por la publicidad o la sociedad, de falta de carácter, de personalidad débil.

La nueva legitimidad del cuidado de sí también se abre paso en expresiones como "sentirse ágil", "no dejarse" o "encontrarse bien". Estas fórmulas se repiten en todos los grupos, ya sea para defenderse de la acusación de preocupación estética, ya sea para afirmar un nuevo tipo de mujer distinto al de las "mujeres de antes" - "se dejaban", "envejecían rápido" - . Estas expresiones tienen éxito por su ambivalencia entre la salud y la estética. "Sentirse ágil" remite directamente a la salud, distanciándose poco de la legitimidad tradicional: se trata de mantener la funcionalidad del cuerpo. "No dejarse" comparte este tímido alejamiento de la legitimidad tradicional de la buena madre. Aunque aúna la salud con la imagen y la autoestima, sólo se atreve a defender el cuidado de sí como negación del contrario: no busco la belleza, intento evitar el deterioro corporal2 ${ }^{25}$. "Encontrarse bien" avanza más: al tiempo que mantiene una doble referencia a la salud física y al bienestar psíquico —que permite jugar con esta ambigüedad-, afirma un derecho al bienestar físico y psíquico que no se reduce a la ausencia de dolencias o a mantener un cuerpo funcional.

La nueva legitimidad del cuidado de sí se afirma más claramente en las expresiones "hay que cuidarse" y "hay que quererse". Estas fórmulas aún son "formaciones de compromiso": comportan buscar la salud y elevar la autoestima manteniendo un cuerpo valorado. Pero se distancian mucho más de la legitimidad tradicional de la buena madre, al afirmar el derecho a un cuidado de sí que no se agota en la función maternal: una misma es el propio objetivo de sus cuidados. Por ello, estas expresiones las introducen preferentemente las participantes más próximas al polo legítimo. Pero el resto las acoge enseguida. Encontramos de nuevo la ambivalencia de la relación entre las madres más "modernas" y el resto: aquéllas pueden ser acusadas desde el esquema tradicional de buena madre, pero también ofrecen caminos para justificar el cuidado de sí.

\footnotetext{
${ }^{24}$ Por ello, sólo se formula cuando el grupo no está debatiendo la legitimidad del deseo de adelgazar 0 cuando se ha desarrollado una complicidad -a todas nos pasa lo mismo.

${ }^{25}$ La publicidad de productos de belleza utiliza el mismo argumento (Márquez Guerrero 2007).
} 


\section{LA CULPA FUE DEL COLESTEROL}

La atención del analista a los vaivenes de la censura estructural permite explicar rasgos de los grupos de discusión difíciles de comprender de otra manera. Un buen ejemplo lo constituye la constante referencia al colesterol en las discusiones. Podríamos pensar que ello se debería a la fuerte incidencia de un colesterol elevado en esta población. Sin embargo, si comparamos las tasas de incidencia, comprobamos que el colesterol se menciona mucho más que otras patologías extendidas como la diabetes o la hipertensión ${ }^{26}$. Otros dos hechos llaman la atención: las tasas de colesterol se mencionan fundamentalmente para justificar comportamientos de restricción alimentaria; habitualmente, no se habla de tener actualmente una elevada tasa de colesterol, sino de una "predisposición", ya sea porque en algún momento se tuvo una tasa elevada o porque la padece algún familiar.

Todo hace pensar que el colesterol adquiere esta relevancia discursiva porque permite legitimar como cuidado de salud las tácticas de adelgazamiento. ¿No se recomiendan para bajar el colesterol los mismos comportamientos —evitar los alimentos grasos, hacer ejercicio- que para un régimen de adelgazamiento? Basta comparar el argumento del colesterol con la posición frente a las otras tasas y enfermedades en la posición mayoritaria. Cuando se trata de cualquier otra enfermedad, la probabilidad de que ésta se manifieste a largo plazo no es razón suficiente para modificar los hábitos cotidianos: el peligro estaría en el "exceso" —en consumir más alimentos malsanos de los que consumimos habitualmente-. Por el contrario, el colesterol siempre aparece en el discurso - excepto, en ocasiones, en las participantes más cercanas a la posición tradicional ${ }^{27}$ - como razón para evitar alimentos demasiado calóricos o grasos. El colesterol sería la "formación de compromiso" más lograda: legitima toda restricción alimentaria como movida por razones de salud.

Nuevamente lideran este discurso las participantes más próximas al polo legítimo. En su caso, no es necesario tener o haber tenido colesterol alto: bajo la concepción de salud como norma, evitar el colesterol es siempre un objetivo legítimo ${ }^{28}$. En la posición mayoritaria, la tasa elevada puede ser una realidad actual: en este caso, justifica de inmediato el control de las ingestas. Recordemos que aquí las tasas que indican predisposición a la enfermedad se asimilan a la enfermedad: cuidarse no sólo

${ }^{26}$ Según la Encuesta Andaluza de Salud de 1999, a la pregunta sobre qué enfermedades se habían padecido, el colesterol era señalado por el 3\% de las personas de 25 a 44 años y por el 10,5\% de las de 45 a 54. La hipertensión era mencionada por un $2,4 \%$ y un $12,6 \%$, respectivamente; y la diabetes, por un $1,3 \%$ y un 5,8\%. Las tasas de incidencia no explican el privilegio discursivo del colesterol.

${ }^{27}$ Así, la participante más tradicional del GD4 ostentaba su "buena boca" alardeando de seguir disfrutando de todo tipo de alimentos grasos a pesar de tener el colesterol alto -que bajaba con pastillas.

${ }^{28}$ Aunque también pueden recurrir al argumento de la predisposición. Es lo que ocurrió con la participante más próxima al polo legítimo del GD4. Ante las acusaciones de ser demasiado "delicada" por su rechazo de los productos grasos, se defendió aludiendo al elevado colesterol de sus padres: ella tenía predisposición. 
es legítimo, sino imperativo. Pero los argumentos se mueven -estratégicamentemás allá: cualquier tasa alta de colesterol en el pasado o cualquier problema con el colesterol de los progenitores indicarían "predisposición" al colesterol. La predisposición es genética o por metabolismo: una no tiene la culpa. La "predisposición"es constante: una ha de cuidar su salud de forma constante. Así, cualquier alza del colesterol —propio o de los progenitores - constituye una ocasión idónea para "controlar" esquivando la acusación de "mirarse demasiado": no es por estética, es por el colesterol.

\section{LA DIFÍCIL TAREA DE LA RESTRICCIÓN ALIMENTARIA}

Hemos visto que el análisis detenido de la evolución de la censura estructural nos permite comprender los vaivenes del discurso en los grupos de discusión. Pero este análisis también nos posibilita entender las tensiones en que se mueven las prácticas. Éstas también son "juzgadas" desde legitimidades que pesan sobre ellas. Lo mostraremos en el resto del artículo.

La mayoría de las participantes describen las tentativas de control del peso como tareas titánicas. Los kilos perdidos con dificultad se recuperan rápidamente, la ropa que por fin salió del armario vuelve a quedar estrecha. De hecho, las condiciones de éxito de una dieta son muy restrictivas ${ }^{29}$, como muestra el grupo de mujeres a dieta y los discursos de las escasas participantes de los otros grupos que han adecuado sus prácticas a las recomendaciones nutricionales.

Ello supone, en primer lugar, un autodominio constante, tener siempre presente el objetivo de control de peso en las prácticas cotidianas: las escasas participantes más próximas al polo legítimo, con su concepción de la salud como norma, han incorporado este objetivo en rutinas donde apenas admiten excepciones; las que hicieron régimen con éxito recurrieron a "tecnologías del yo" — vigilar diariamente el peso, anotar las ingestas, seguir el menú prescrito- para controlarse. Situación opuesta a la de la mayoría de las participantes: el objetivo de control del peso no modela las prácticas cotidianas, que se rigen por otras lógicas.

Un segundo elemento son los gustos alimentarios incorporados en el habitus. Las participantes más ascéticas muestran su "asco" por los productos grasos: mantener una dieta baja en calorías no implica un combate constante contra las preferencias corporales. Nada de esto sucede para la mayoría; los alimentos preferidos son alimentos calóricos: "Las berzas sin tocino no saben igual", "lo que más bueno está es lo que engorda". Podemos interpretar las múltiples afirmaciones en este sentido en los grupos como

\footnotetext{
${ }^{29}$ Por ello, tampoco parecen reunirse en muchas mujeres de clases medias. Limitamos nuestra argumentación a las madres de clases populares -sin prejuzgar sobre su extensión a otros medios sociales- para ceñirnos al material empírico del que parte este artículo. Para otros medios sociales (Charles y Kerr 1988: 141-164; Germov y Williams 1996; 1999; Gracia 1996; 1997).
} 
manifestaciones de un habitus alimentario popular. El habitus alimentario de las clases populares se ha conformado durante generaciones en una situación donde coexistían la escasez económica con los elevados gastos calóricos que requería el trabajo físico. De ahí que se privilegiaran los alimentos con una buena relación calorías/precio. De ahí que se denominen comidas "con fundamento" o que "tienen mucho alimento" a las que proporcionan un generoso aporte calórico. Adelgazar supone combatir los gustos incorporados en una desigual batalla entre unas intenciones inconstantes y una atracción constante por alimentos calóricos.

La dificultad de adelgazar también pone en juego dimensiones simbólicas. La legitimidad del cuidado de sí no sólo se juega en el adelgazamiento como fin, sino también en los medios para conseguirlo. Determinados medios pueden aceptarse cuando el objetivo de adelgazar se ve legítimo - cuando se trata de la salud, especialmente- pero ser impugnados cuando esta legitimidad puede ser objeto de sospecha. $Y$ a la inversa: "cuidarse" puede ser aceptable cuando no interfiere con las obligaciones de una buena madre, pero recibir aceradas críticas cuando comporta relegar estas obligaciones. Aquí también entre el polo legítimo y en el resto de madres se da una relación ambivalente: las primeras pueden ser alabadas por su capacidad de "controlar", pero también recibir virulentos ataques por faltar a valores fundamentales - como tener "buena boca" - 0 a las obligaciones de la buena madre. Entre el polo legítimo y el resto se juega una relación de atracción y repulsión: las primeras pueden ser objeto de severas críticas, pero ser seguidas cuando ofrecen argumentos o prácticas que legitimen el cuidado de sí.

Esta ambivalencia se ve bien en los dos marcos de sentido que se aplican a las prácticas de restricción alimentaria. Éstas pueden comportar el reproche de "mirarse demasiado", pero también ser alabadas como muestra de "fuerza de voluntad". Las participantes que llevan dietas bajas en calorías pueden ser inculpadas, pero también envidiadas por su capacidad de "controlar". Frente a la continua cesión a su gusto por los alimentos calóricos del resto de madres, ellas poseerían un admirable autodominio. Cuando adelgazar es legítimo, la diferencia se establece entre quien tiene "fuerza de voluntad" y quien carece de ella ${ }^{30}$.

Puede verse el peso de este marco de sentido en el ambiguo estatus de los productos light. Como veremos, para la mayoría constituyen un práctico recurso para conciliar la reducción calórica con la organización cotidiana de las comidas y con el habitus alimentario. Sin embargo, aunque proliferen las referencias espontáneas a productos light, cuando la conversación se centra en ellos, se desencadena una competencia simbólica por mostrar que se consumen productos "normales". La única posición legítima es negar o minimizar su consumo. Aquí juegan varios factores. En primer lugar, los

\footnotetext{
${ }^{30}$ Este marco de sentido ha dominado durante el siglo XX en la visión de la obesidad: ésta delataría una falta de autocontrol. Esta condena moral de la obesidad jugó un papel importante en su medicalización (Levenstein 1988; 2003; Fischler 1995: 297-370; Germov y Williams 1999; Poulain 2002: 95-128; Parham 1999; Stearns 2002).
} 
productos light se enfrentan a la identificación de lo sano con lo "natural" (Martín Criado 2004): son productos industriales más procesados que los "normales". En segundo lugar, consumir productos light cuando una está sana se opone a los esquemas de "no mirarse demasiado" y de "saber disfrutar" - los alimentos light, al no ser "naturales", tendrían sabores degradados-. Pero incluso cuando se ve legítimo adelgazar, los productos light son sospechosos: evidencian incapacidad de autocontrol. De ahí que en todos los grupos se repita una anécdota: una mujer consume light para adelgazar pero, confiada en ingerir menos calorías, termina comiendo el doble. Estas anécdotas identifican el consumo light con la incapacidad de autodominio: quien consume light lo hace por falta de fuerza de voluntad; por ello, es normal que caiga en su propia trampa y termine comiendo mucho más. Frente al control verdadero mediante fuerza de voluntad, el consumo light delata el control ilusorio de quien no se sabe controlar.

"Controlarse" comporta así un nuevo marco de legitimidad cuando adelgazar es aceptable. Por ello, cuando se trata de enfermedades, tasas de colesterol elevadas u obesidades desmedidas, todas las participantes coinciden: en estos casos, controlarse no es "mirarse demasiado", sino una obligación ${ }^{31}$. La restricción alimentaria adquiere un valor positivo. Aquí la obesidad, lejos de ser signo de una madre entregada hasta el límite, evidencia su incapacidad de autodominio, su glotonería ${ }^{32}$. Sin embargo, el consenso se disuelve fuera de estos casos bien delimitados. La restricción cotidiana de alimentos calóricos es tachada de "mirarse demasiado", de estar "obsesionada", de no "saber disfrutar". El control ya no es una virtud: indica una preocupación desmedida por sí misma que lleva a descuidar valores más importantes y sus mismas obligaciones con la familia. Estos reproches nos muestran los obstáculos que suponen determinados esquemas simbólicos para el control alimentario entre muchas madres de clases populares.

Las dificultades se presentan, primero, en las comidas fuera de casa. Las "tapitas" 0 las fiestas se mencionan repetidamente como situaciones donde se gana peso. Ello nos muestra la débil interiorización del objetivo de adelgazar: la pretensión de "controlarse" se desvanece en las ocasiones festivas. También nos muestra la importancia de tener

\footnotetext{
${ }^{31} \mathrm{En}$ el GD4, en las disputas entre la participante más próxima al polo legítimo -que practicaba una constante restricción calórica- y la que más alardeaba de su "buena boca", la mayoría se ponía del lado de ésta. Sin embargo, cuando salió a relucir el elevado colesterol de la participante con buena boca, todas cambiaron de bando para alabar a la que sabía "controlarse" y censurar a la participante que, a pesar de su alto colesterol, seguía comiendo lo que le gustaba sin importarle la grasa. La legitimidad de controlar era tan aplastante que la misma que había alardeado de "no mirarse" tuvo que defenderse argumentando lo contrario: yo también me controlo, como embutidos de pavo, sólo me excedo ocasionalmente...

${ }^{32} \mathrm{En}$ el GD3, la participante que había intentado sin éxito sucesivos regímenes de adelgazamiento insistía en que no estaba gorda por comer, sino por razones ajenas a su voluntad: desorganización horaria, constitución fisiológica -propensión a retener líquidos- o psíquica -"nerviosismo" que le haría comer rápido-... Estas justificaciones, independientemente de su veracidad, nos muestran el peso de las acusaciones de glotonería y de falta de fuerza de voluntad asociadas al estigma de gorda.
} 
"buena boca" y "saber disfrutar": el autodominio va contra un "saber vivir" y contra una integración en el grupo que suponen comer y disfrutar en abundancia de la comida que todos comen y disfrutan. De ahí los reproches cuando alguna participante muestre su asco por estos alimentos o sus tácticas para evitar los productos grasos de estas comidas comunes: tú eres demasiado delicada. Ser "remilgada" evidencia un rechazo a integrarse - "hay que echarla de comer aparte"-, cuando no un afán de superioridad - "se cree muy especial" - y una incapacidad para gozar de los momentos buenos de la vida.

Las dificultades también se presentan en el hogar. Dado que en las clases populares la comida familiar suele ser rica en calorías, la restricción calórica implicaría, bien modificar la alimentación familiar, bien tener una dieta individualizada.

La primera opción ni siquiera es contemplada por la mayoría: supondría imponer sus preferencias sobre las de los hijos y el marido. La buena madre no impone sus gustos: estos quedan en segundo plano frente a las preferencias del marido e hijos, que empujan —los maridos hacia comidas tradicionales, los hijos hacia comidas "juveniles" 0 "infantiles" - hacia alimentos calóricos. La buena madre mira antes por sus hijos que por sí misma y procura hacerles las comidas que les gustan. Ello provoca prácticas contrarias al control del peso: cocinar los alimentos preferidos por los hijos - habitualmente ricos en calorías - y tener la nevera llena de estos productos - una trampa para la madre que quiera "controlar".

La segunda solución sería una dieta separada. Esta opción tampoco aparece espontáneamente en el discurso: muchas identifican comprar productos de régimen con poner a dieta a toda la familia. Esto se ve bien en la siguiente intervención: yo no como productos light porque mis hijos están enclenques.

"Yo no lo hago, porque entro por la puerta y mis dos niños son enclenques, pues tampoco voy a comer desnatados, por Dios, porque son dos palillos de dientes. Si a mí lo que me entra es inflarlos. Tengo dos palillos de dientes, ¿me voy a poner ahora a darles cosas light? Por Dios bendito, yo lo que quiero es que tenga bastante fundamento" (GD4).

La buena madre cocina para la familia, no para sí misma. Hacerse una comida aparte, estando sana, es darse demasiada importancia, pensar en una misma antes que en los hijos. De ahí uno de los principales argumentos contra la comida de régimen: "a la larga o a la corta te pones a dieta y te sale carísimo porque pones a toda la familia, porque son cosas buenas" (GD3). Hacer régimen es poner a la familia a régimen. Ello atenta contra otro valor de la buena madre de clases populares: saber economizar. La buena madre cocina platos sabrosos sin despilfarrar. Ahora bien, la comida de régimen suele invertir la relación calorías/precio de la "normal": frente a los alimentos "normales", calóricos a bajo precio, los de régimen ofrecen menos calorías por más dinero. La madre que pone a la familia a régimen, en vez de ahorrar, despilfarra; mira por sí misma en vez de por la familia y el dinero familiar. 
Por ello, son las participantes más próximas al polo legítimo quienes plantean reservarse alimentos especiales o tener una dieta separada. Al ver legítimo el cuidado de sí, exponen abiertamente esta práctica. Ello les vale las críticas del resto: te reservas los alimentos más caros y les das a tus hijos comidas inferiores. La buena madre no come mejor que sus hijos: "yo no me voy a comer un pez espada y ponerle a mi hijo un huevo frito" (GD3). Reservarse alimentos mejores es un acto de egoísmo imperdonable en una madre.

Pero el polo legítimo también ofrece argumentos para conciliar el cuidado de sí con la legitimidad de la buena madre. La comida separada puede justificarse aludiendo a las distintas "necesidades" nutricionales de madre e hijos. Cada cuerpo y edad tiene necesidades energéticas distintas; por tanto, requiere una alimentación específica. Este argumento es bien acogido por el resto de madres: concilia el cuidado de sí con el papel de guardiana de la salud familiar. Al dar a sus hijos comidas más calóricas, la madre tendría en cuenta que "queman más": gestionaría la alimentación familiar de forma más atenta e individualizada. La alusión a las distintas necesidades compatibiliza el cuidado de sí con el papel de buena madre. Aquí también tenemos una relación ambivalente entre el polo legítimo y el resto de madres: éstas reafirman el valor de la entrega frente a las nuevas prácticas de cuidado de sí, al tiempo que están dispuestas a acoger aquellos argumentos que les permitan conciliar esas prácticas con el papel de buenas madres.

\section{LA LÓGICA DE LAS PEQUEÑAS SUSTITUCIONES}

En la mayoría de los casos la legitimidad de hacer una comida separada es débil: sólo se justifica en caso de enfermedades, tasas elevadas, obesidades extremas o, como mucho, en breves períodos ${ }^{33}$. Para la mayoría, el discurso de la diferencia de necesidades sólo justifica comer menos cantidad del plato común o realizar pequeñas sustituciones de alimentos que no interfieran con la comida principal. Ello nos muestra la persistencia de la división tradicional de género, incorporada en el esquema de la madre entregada.

La fortaleza de la división de género se ve en la posición inversa de maridos y mujeres frente a la dieta del cónyuge. El marido, habitualmente, no varía su alimentación cuando la mujer hace régimen. La situación se invierte cuando el hombre —normalmente por consejo médico- hace régimen: la mujer se esfuerza en seguir las recomendaciones médicas y adapta su dieta - y en parte la familiar - a la del marido.

Esta situación también nos muestra cómo, dentro del esquema tradicional de buena madre, determinadas circunstancias permiten seguir dietas hipocalóricas de forma

\footnotetext{
${ }^{33}$ Ésta es una de las condiciones del éxito de las dietas-milagro: abren un período extraordinario, pero corto, de restricciones alimentarias. Permiten un paréntesis en el que la mujer puede dedicarse a sí misma: una práctica aceptable -y negociable- por su brevedad, por su carácter extra-ordinario.
} 
legítima: cuando se justifican como cuidado de la salud familiar. Si la mujer sigue la dieta del marido, también se debe a que constituye una ocasión propicia para "controlar": adecuando su dieta a la del cónyuge, reduce calorías al tiempo que cumple como buena esposa. Si la jerarquía de género, cuando el marido está sano, obstaculiza la pretensión de adelgazar de la mujer, la situación se invierte cuando aquél hace régimen: aquí la misma jerarquía de género propicia el control de peso femenino. Una dinámica similar puede darse con los hijos ${ }^{34}$.

Fuera de estas excepcionales "condiciones propicias", todo presiona contra el mantenimiento de una dieta baja en calorías: el valor de la buena madre entregada, los gustos incorporados, la débil interiorización del objetivo de adelgazar, los esquemas de "saber disfrutar", tener "buena boca" y "no mirarse demasiado". Por ello, el objetivo de adelgazar habitualmente se traduce en pequeños controles cotidianos que constituyen otras tantas "formaciones de compromiso" para conciliar un inicio de cuidado de sí con el papel de buena madre. De ahí su carácter fragmentario: controles diminutos y accesorios, que no interfieren con la rutina alimentaria familiar ni cuestionan los valores de la buena madre, permiten cierto cuidado de sí al tiempo que se mantiene la "buena boca" capaz de "comer de todo" y de disfrutar de la "verdadera comida". De ahí que estas prácticas se den al margen de las comidas principales: estos controles - restricciones puntuales, sustituciones de alimentos "normales" por otros menos calóricos ${ }^{35}$ o por combinaciones supuestamente adelgazantes ${ }^{36}$ - son más probables en las ingestas consideradas accesorias - desayuno, aperitivo, bebidas, postre.

\footnotetext{
${ }^{34}$ Una participante del GD1 relataba cómo sus hijas universitarias, preocupadas con su peso, habían introducido todo tipo de ensaladas como plato principal. Estas ensaladas, desde el esquema tradicional, no podrían ser el plato principal de una "verdadera comida". Sin embargo, la madre las acepta rápidamente. Por un lado, tienen la legitimidad de estar elaboradas con componentes "naturales" (verduras frescas, atún...). Por otro lado, el estatus de universitarias de sus hijas valoriza simbólicamente sus innovaciones. Ello le permite a la madre "aligerar" el trabajo de cocinar y comer alimentos menos calóricos al tiempo que preserva la legitimidad de buena madre: ella adapta su dieta a la de sus hijas, no a la inversa.

${ }^{35}$ Aquí tienen su papel los alimentos light: permiten reducir la ingesta calórica sin variar los hábitos alimentarios y, mientras no afecten a la comida principal, sin interferir con ésta. Sus inconvenientes serían el precio -cuando fueran más caros- y el sabor -cuando éste fuera muy distinto del "normal"-. A igualdad de precio y sabor, constituirían una solución ideal. De ahí su consumo -aunque éste suela negarse.

${ }^{36}$ En los grupos se mencionan numerosas combinaciones de alimentos que tendrían la virtud de adelgazar. Estas combinaciones son recogidas en parte porque se corresponden con una concepción tradicional de la salud: actuarían como alimentos-remedio de la obesidad. Pero la confianza en ellas -o en los productos "milagrosos" para adelgazar- también nos remite a la dificultad de mantener un "régimen" prolongado. Si estas madres están dispuestas a acoger los "remedios" más variados contra la obesidad, no se debe a una falta de conocimiento nutricional o a una especial credulidad, sino a que prometen resolver el dilema de pretender un objetivo cuando faltan las condiciones para conseguirlo.
} 


\section{El ÉXITO de LOS PASEOS del COLESTEROL}

Las tácticas de restricción de calorías despiertan agudas controversias en los grupos. Frente a ellas, una actividad obtiene la aprobación unánime y entusiasta: pasear. A diferencia de las otras prácticas de cuidado de sí, el paseo no suscita sospechas: actividad sana y deseable, constituye una forma legítima de cuidarse.

Ello se debe en primer lugar a que no interfiere con las comidas familiares: no se trata de realizar comidas separadas, de imponer alimentos que el resto no aprecia, de comprar productos más caros. La actividad del paseo es externa al papel de la mujer en la alimentación familiar.

En segundo lugar, pasear puede presentarse como una actividad de salud, más que de estética. Se trata de "mantenerse ágil" o de bajar el colesterol: las múltiples recomendaciones médicas del ejercicio físico permiten legitimar la actividad. Además, es una actividad productiva, implica un esfuerzo: se trata de "moverse", de "no quedarse sentada", de "no ser perezosa". El ejercicio físico del paseo puede presentarse como una forma de ocio productivo.

Pero el paseo es también una actividad placentera. Frente a las penosas restricciones y sustituciones alimentarias -en incesante lucha contra los gustos incorporados-, pasear constituye una liberación. Actividad externa y generalmente grupal, pasear permite escapar a la reclusión en el hogar y compartir con otras mujeres el tiempo, la conversación, el cuidado de sí. Pasear no es sólo una actividad física, sino también un período de sociabilidad femenina, un recreo legítimo.

No podemos minusvalorar la importancia de este aspecto. El oficio de ama de casa supone una multiplicidad de actividades solitarias y poco reconocidas. Además, por la fuerte división de género, las preocupaciones del ama de casa son poco comprendidas por los maridos. Las tareas y tiempos compartidos con otras mujeres en la misma situación cumplen múltiples funciones: salida del aislamiento en el hogar, intercambio de consejos, favores, informaciones; pero sobre todo, apoyo psíquico. Los espacios de sociabilidad entre amas de casa permiten compartir preocupaciones y soluciones con otras mujeres que comprenden la importancia de estos acontecimientos y ofrecen consejo porque comparten el mismo oficio y se enfrentan a situaciones similares con recursos similares, porque sufren las mismas dolencias y tensiones. Frente a los maridos, para quienes estos problemas son "cosas de mujeres", las otras madres de medios sociales similares comprenden y valoran las preocupaciones que jalonan la jornada del ama de casa. A medida que se cierran las puertas de los hogares, que desaparecen los espacios tradicionales de esta sociabilidad de amas de casa, cobran importancia los nuevos espacios donde pueda desarrollarse: asociaciones, cursillos, etc. (Murillo 1996: 143). Es aquí donde los paseos ocupan un lugar fundamental: combinan el cuidado de sí físico con el psíquico, la liberación de la reclusión con la legitimidad de cuidar la salud, el ejercicio físico con la conversación.

Pasear para bajar el colesterol. Cada día es más frecuente encontrar en nuestros pueblos y ciudades grupos de mujeres dedicadas a esta actividad. Mediante ella, 
compaginan el cuidado de sí con la legitimidad tradicional del ama de casa. El éxito de estos paseos nos muestra la persistencia del modelo tradicional de buena madre. Pero también nos muestra un camino mediante el que avanza, a hurtadillas, una nueva legitimidad del cuidado de sí de la mujer: de una mujer con objetivos propios, de una mujer cuyo valor no sea únicamente el de buena madre.

\section{Conclusiones}

El objetivo de este artículo ha sido mostrar la potencialidad de analizar los discursos como prácticas mediante las cuales se maneja la imagen ante determinados interlocutores en determinadas situaciones. Para ello hemos tomado un caso concreto: las oscilaciones y contradicciones del discurso de madres de clases populares en torno al control del peso.

Estas contradicciones nos remiten a la difícil posición entre dos normas opuestas. Por un lado, la nueva norma de delgadez. Por otro, el valor de la buena madre entregada. Mientras la primera demanda un constante control de las ingestas, el esquema tradicional de buena madre exige que la mujer tenga en cuenta los intereses familiares antes que los propios, y que sólo "mire por sí misma" en caso de enfermedad. Desde este esquema, preocuparse por el peso sólo se justifica en caso de obesidad desmedida o de dolencias. De ahí que el discurso oscile tanto, que afirme y niegue la pretensión de adelgazar, o que la intente legitimar por razones de salud.

Esta tensión entre dos imperativos opuestos también nos permite comprender las prácticas de control de peso. Seguir una dieta hipocalórica requeriría cambiar la alimentación familiar o llevar una dieta individualizada. Ambas se hallan contra el valor de la buena madre entregada. La primera, porque supondría una inversión de valores: en vez de supeditar sus deseos a la familia, la madre que modificara la dieta familiar para adelgazar supeditaría los deseos familiares a los propios. La segunda, porque muchos alimentos de dieta son más caros que los normales: la buena madre no come mejor que sus hijos. De ahí que las tácticas de control de peso se reduzcan a pequeñas sustituciones o restricciones que no interfieran con las comidas familiares.

La atención a las tensiones entre estas legitimidades contradictorias nos permite asimismo comprender prácticas como los paseos del colesterol. Por un lado, el argumento de la "predisposición" al colesterol supone la "formación de compromiso" más lograda entre la pretensión de control de peso y la legitimidad de la buena madre: al exigir el control del colesterol los mismos comportamientos que el control de peso, permite legitimar con razones de salud las tácticas de adelgazamiento. Por otro lado, el paseo, a diferencia de las restricciones alimentarias, es una práctica legítima -no interfiere con la alimentación familiar, es un ocio productivo-y agradable - permite compartir un espacio de sociabilidad con otras mujeres y escapar a la reclusión doméstica.

Los sujetos utilizan estrategias de presentación de sí en sus discursos. Pero también lo hacen en sus comportamientos. El análisis detenido de sus estrategias discursivas, 
de las tensiones que pretenden superar, nos permite entender las tensiones en que se mueven las prácticas y las estrategias para hacerles frente.

\section{RefERENCIAS BibLIOGRÁfICAS}

Adam, P. y C. Herzlich. 2002. Sociologie de la maladie et de la medicine. París: Nathan.

Badinter, E. 1980. L'Amour en plus. Histoire de l'amour maternel (XVIle-XXe siècle). París: Flammarion.

Baudelot, Ch., F. Leclercq, A. Chatard, B. Gobille y E. Satchkova. 2005. Les effets de l'éducation. París: La Documentation française.

Boltanski, L. 1975. Los usos sociales del cuerpo. Buenos Aires: Periferia.

Bourdieu, P. 1985. ¿Qué significa hablar? Economía de los intercambios lingüísticos. Madrid: Akal.

Bourdieu, P. 1988. La distinción. Madrid: Taurus.

Charles, N. y M. Kerr. 1988. Women, food and families. Manchester: Manchester University Press.

Contreras, J. 2005. "La obesidad: una perspectiva sociocultural." Pp. 155-180 en ¿Cómo comemos? Cambios en los comportamientos alimentarios de los españoles. Coordinado por Díaz Méndez, C. Madrid: Fundamentos.

Dema Moreno, S. 2006. Una pareja, dos salarios. El dinero y las relaciones de poder en las parejas de doble ingreso. Madrid: CIS - Siglo XXI.

Espeitx, E. 2005. "La construcción del cuerpo a través de la alimentación: la salud y la imagen corporal". Pp. 129-154 en ¿Cómo comemos? Cambios en los comportamientos alimentarios de los españoles. Coordinado por Díaz Méndez, C. Madrid: Fundamentos.

Fischler, C. 1995. El (h)omnívoro. El gusto, la cocina y el cuerpo. Barcelona: Anagrama.

Freidson, E. 1978. La profesión médica. Barcelona: Península.

Germov, J. y L. Williams. 1996. "The Epidemic of Dieting Women: The Need for a Sociological Approach to Food and Nutrition." Appetite 27: 97-108.

Germov, J. y L. Williams. 1999. "Dieting Women. Self Surveillance and the Body Panopticon." Pp. 117132 en Weighty Issues. Fatness and Thinness as Social Problems. Coordinado por Sobal, J. y D. Maurer. Nueva York: Aldine de Gruyter.

Goffman, E. 1971. La presentación de la persona en la vida cotidiana. Buenos Aires: Amorrortu.

González Turmo, I. 1997. Comida de rico, comida de pobre. Evolución de los hábitos alimenticios en el Occidente andaluz (Siglo XX). Sevilla: Secretariado de Publicaciones de la Universidad de Sevilla.

Gracia Arnáiz, M. 1996. Paradojas de la alimentación contemporánea. Barcelona: Icaria. 
Gracia Arnáiz, M. 1996. Paradojas de la alimentación contemporánea. Barcelona: Icaria.

Gracia Arnáiz, M. 2007. "Comer bien, comer mal: la medicalización del comportamiento alimentario." Salud Pública de México 49: 236-242.

Grignon, C. y Ch. Grignon. 1980. "Styles d'alimentation et goûts populaires." Revue Française de Sociologie 21: 531-569.

Hays, S. 1988. Las contradicciones culturales de la maternidad. Barcelona: Paidos.

Herzlich, C. y J. Pierret. 1984. Malades d'hier, malades d'aujourd'hui. París: Payot.

Kauffman, J. C. 1993. Sociologie du couple. París: Presses Universitaires de France.

Kniebiehler, Y. 2000. Histoire des mères et de la maternité en Occident. París: Presses Universitaires de France.

Lahire, B. 1998. L'homme pluriel. París: Nathan.

Levenstein, H. 1988. Revolution at the Table. The Transformation of the American Diet. Nueva YorkOxford: Oxford University Press.

Levenstein, H. 2003. Paradox of Plenty. A social history of eating in modern America. Berkeley-Los Angeles: University of California Press.

Márquez Guerrero, M. 2007. "Análisis semiótico del concepto actual de 'Belleza' en la publicidad dirigida a la mujer." Trastornos de la conducta alimentaria 5: 483-506.

Martín Criado, E. 1991. "Del sentido como producción: elementos para un análisis sociológico del discurso." Pp. 187-212 en El pluralismo metodológico en la investigación social, editado por Latiesa, M. Granada: Servicio de Publicaciones de la Universidad de Granada.

Martín Criado, E. 1997. "El grupo de discusión como situación social." Revista Española de Investigaciones Sociológicas 79: 81-112.

Martín Criado, E. 1998. "Los decires y los haceres." Papers 56: 57-71.

Martín Criado, E. 2004. "El valor de la buena madre. Oficio de ama de casa, alimentación y salud entre las mujeres de clases populares." Revista Española de Sociología 4: 93-118.

Martín Criado, E. 2007. "La dieta desesperada. Algunas condiciones sociales que obstaculizan el control del peso entre madres de clases populares." Trastornos de la conducta alimentaria 6: 578-599.

Martín Criado, E. y J. L. Moreno Pestaña. 2005. Conflictos sobre lo sano. Sevilla: Consejería de Salud de la Junta de Andalucía.

Meil Landwerlin, G. 1997. "La redefinición de la división del trabajo doméstico en la nueva familia urbana española." Revista Española de Investigaciones Sociológicas 80: 69-93. 
Murillo, S. 1996. El mito de la vida privada. De la entrega al tiempo propio. Madrid: Siglo XXI.

Parham, E. S. 1999. "Meanings of Weight among Dietitians and Nutritionists." Pp. 183-205 en Weighty Issues. Fatness and Thinness as Social Problems. Coordinado por Sobal, J. y D. Maurer. Nueva York: Aldine de Gruyter.

Poulain, J. P. 2002. Sociologies de l'alimentation. Les mangeurs et l'espace social alimentaire. París: Presses Universitaires de France.

Schwartz, H. 1986. Never Satisfied. A Cultural History of Diets, Fantasies and Fat. Nueva York: The Free Press.

Solé, C. y S. Parella. 2004. "'Nuevas' expresiones de la maternidad. Las madres con carreras profesionales 'exitosas'." Revista Española de Sociología 4: 67-92.

Stearns, P. N. 2002. Fat History. Bodies and Beauty in the Modern West. Nueva York y Londres: New York University Press.

Valiente Fernández, C. 1997. “¿Algo más que 'ganadores del pan’?: El papel de los hombres en el ámbito familiar en España (1975-1996)." Revista Española de Investigaciones Sociológicas 79: 221-243.

ENRIQUE MARTíN CRIADO es profesor de la Universidad de Sevilla. Miembro del colectivo Denunciemos los abusos patronales (www.abusospatronales.es). Ha publicado Producir la juventud (1998), Les deux Algéries de Pierre Bourdieu (2008), La escuela sin funciones (2010) y, en coautoría, Familias de clase obrera y escuela (2000), Pierre Bourdieu: Las herramientas del sociólogo (2004) y Conflictos sobre lo sano (2005). Actualmente pretende publicar un libro titulado La escuela sin funciones.

RECIBIDO: $05 / 03 / 08$

ACEPTADO: 26/11/08

Publicado on-line: 22 de abril de 2010 